\title{
Quantification of Heat Flows Through Building Entrance Doors on a Winter Day
}

\author{
Daeho Kang \\ New York City College of Technology, City University of New York, Brooklyn, NY, USA
}

\begin{abstract}
The current methods for the prediction of the heat flow through building entrance doors have been used for years while involved with a certain degree of uncertainty. This paper describes an experimental method that accurately quantified such heat flow. The experiment monitored local environmental parameters in a college building on a cold winter day. The results of the experiment demonstrated that the experimental method is viable to accurately estimate the heat flow throughout the entrance doors and the presence of a vestibule moderated heat losses from the conditioned area. The results will be used for validating the existing methods.
\end{abstract}

\section{Introduction}

Natural ventilation has been widely used in various ways in order to reduce building cooling loads and to maintain indoor air quality (Chen, 2009). As ventilation and infiltration take a large portion of building loads, many studies have investigated methods to implement various strategies for maintaining indoor environments in buildings (Han et al., 2015; Chiu and Etheridge, 2004; Goubran et al., 2017). Methods have been developed to estimate wind pressure distribution on outside building surfaces (Chiu and Etheridge, 2004; Muehleisen and Patrizi, 2013; Younes et al., 2011; Shaw and Tamura, 1977). Swami and Chandra (1988) developed empirical models that predict the wind pressure coefficient $C p$. Studies have done wind tunnel tests and presented surface-averaged wind pressure coefficient (Ernest et al., 1992; Muehleisen and Patrizi, 2013; Chiu and Etheridge, 2004; Goubran et al., 2017). These results and models have been implemented in building energy simulation programs such as EnergyPlus and ESP-r (E+ ESP-r). In addition, many models have been developed to predict infiltration rates. They include single zone models such as LBL model and AIM-2 model (Walker and Wilson, 1990) as well as multi-zone models such as COMIS and CONTAM (Dols and Polidoro, 2015; Feustel, 1998).

The majority of the previous works focused on natural ventilation and infiltration rates through openings and cracks on building envelope as discussed above. Airflow through building entrance doors have been relatively less studied while it involves considerable energy losses (Cho et al., 2010; Yuill et al., 2000; Han et al., 2015). Yuill et al. (2000) investigated infiltration rates through automatic doors and developed an empirical model to estimate infiltration as a function of door usage rate, the differential pressure across doors, and door geometry. Kohri (2001) developed a simulation method to estimate door opening areas and approximated outdoor airflows rates through two different doors in an office building. Cho et al. (2010) estimated the energy saving impacts of ASHRAE 90.1 vestibule requirements by using EnergyPlus simulation program. The simulations predicted that vestibules in a strip mall resulted in the average percentage energy saving of $5.61 \%$. Mahajan et al. (2015) proposed a model that predicts airflow rates through automatic doors for low-rise buildings. The results of a case study in a restaurant building showed that double sliding doors with a vestibule were more effective than double swing doors with a vestibule.

The accurate prediction of wind-driven airflow rates through building entrance doors is very difficult since wind profiles around buildings vary with time not only because of the nature of wind but also because of such physical conditions of buildings as orientation, height, and terrains. In general, the heat flows across building entrance doors have been determined based on the infiltration rates estimated by the methods discussed ahead. Such methods involve with some degree of uncertainty and the predictions by the methods are typically inaccurate. To that end, an experimental method has been developed to accurately estimate heat flows through building entrance doors. It describes the experimental method and presents the results of the experiment.

\section{Method}

\section{Building}

A field measurement was undertaken in an 8-story campus building at New York City College of Technology of the City University of New York on a cold winter day. The building is located in Brooklyn, NY, USA. Four swing doors with 180-degree swing capacity are on the outer side of a vestibule and four swing doors with 90-degree swing capacity toward the outside are on the opposite side as shown in Figure 1. One of the four swing doors on each side is an automatic door. Figure 1 illustrates the shape of the vestibule space and the measuring parameters. A fan coil unit in the vestibule provided heating during the course of the measurement while a central air-conditioning system conditioned the lobby through ceiling diffusers. A special feature of the 
building entrance area is a glass structure in front of the entrance doors along the south and east sides of the main entrance area as shown in Figure 1. The glass structure blocks the direct winds from the south and east and the wind profile in the area differed from the street level. The areas of the vestibule and the lobby are approximately $13.3 \mathrm{~m}^{2}$ and $118.4 \mathrm{~m}^{2}$, respectively.
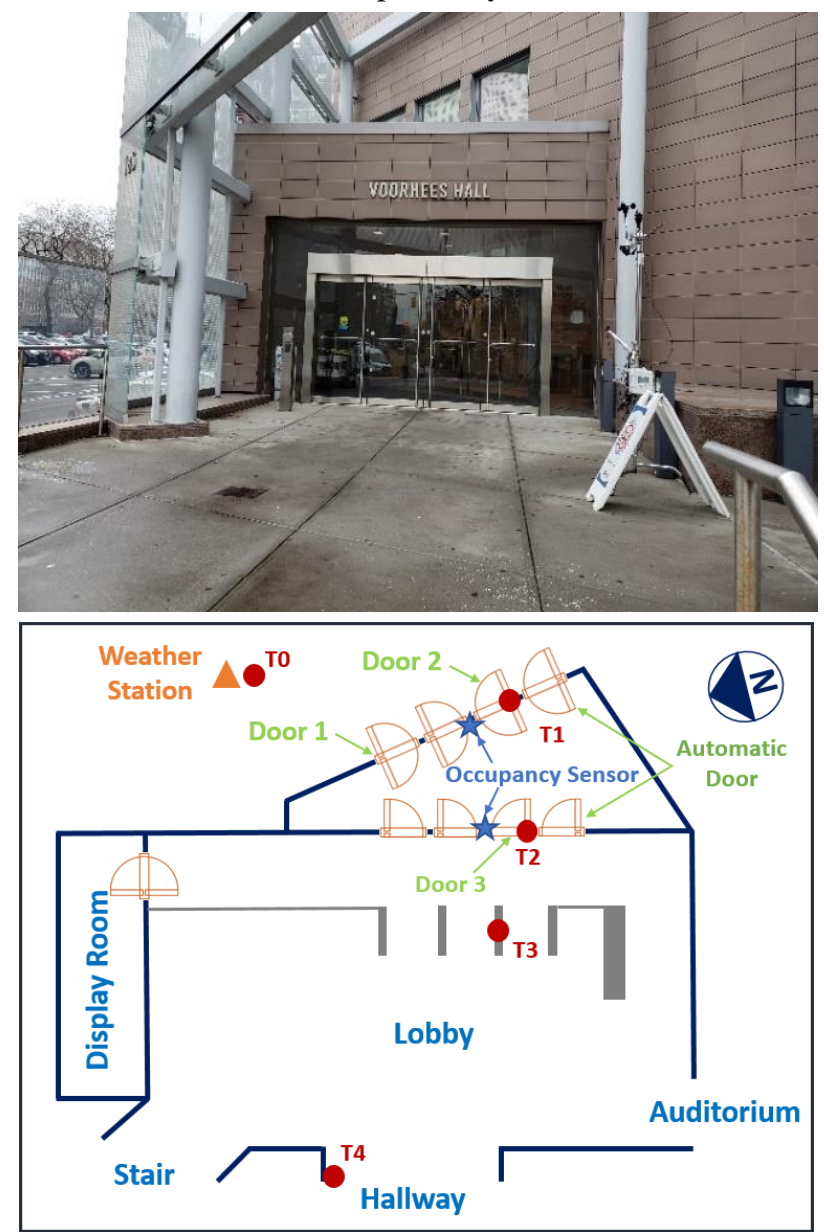

Figure 1: Front and plan views of the building lobby area and the measuring positions of the parameters.

\section{Instrumentation}

The measurement monitored both outdoor and indoor environments. Table 1 shows the instruments and sensors used for the measurement. A HOBO U30 data logger monitored local wind profiles in front of the entrance doors within approximately 5 meters. HOBO MX2301 temperature/RH data logger recorded the outdoor thermal environment. An occupancy-light data logger HOBO UX

Table 1: Measurement parameters and the specification of the instruments and sensors.

\begin{tabular}{|l|l|c|c|c|c|}
\hline \multicolumn{1}{|c|}{ Measurement } & \multicolumn{1}{|c|}{ Instrument } & Interval & Range & Accuracy & Resolution \\
\hline OA Temp/RH & HOBO MX2301 & $1 \mathrm{~min}$ & $-40-70^{\circ} \mathrm{C}$ & $\pm 0.2^{\circ} \mathrm{C}$ & $0.04^{\circ} \mathrm{C}$ \\
\hline Indoor Temperature & HOBO U10 & $1 \mathrm{~min}$ & $-20-70^{\circ} \mathrm{C}$ & $\pm 0.53^{\circ} \mathrm{C}$ & $0.14^{\circ} \mathrm{C}$ \\
\hline Door Usage & HOBO UX90-6M & $1 \mathrm{sec}$ & $12 \mathrm{~m} / 102^{\circ}$ & - & - \\
\hline Air Velocity (AV) & TSI Alnor Velometer AVM 430 & - & $0-20 \mathrm{~m} / \mathrm{s}$ & $\pm 5 \%$ & $0.01 \mathrm{~m} / \mathrm{s}$ \\
\hline $\begin{array}{l}\text { Differential Pressure } \\
\text { (DP) }\end{array}$ & $\begin{array}{l}\text { HOBO T-VER-PXU-L Differential } \\
\text { Air Pressure Transducer }\end{array}$ & - & $249 \mathrm{~Pa}$ & $\pm 1 \%$ & - \\
\hline Wind Speed (WS) & HOBO U30 & $1 \mathrm{~min}$ & $0-76 \mathrm{~m} / \mathrm{s}$ & $\pm 4 \%$ & $0.5 \mathrm{~m} / \mathrm{s}$ \\
\hline Wind Direction (WD) & HOBO U30 & $1 \mathrm{~min}$ & $0-355^{\circ}$ & $\pm 5^{\circ}$ & $1.4^{\circ}$ \\
\hline
\end{tabular}

90 collected data for the frequency and time of door openings every second. HOBO U10 temperature data ogger measured indoor air temperature at various positions as indicated in Figure 1. Air velocity and differential pressure across the entrance doors were manually measured by TSI Alnor velometer and HOBO T-VER-PXU-L Differential Air Pressure Transducer, respectively. Hobo U 10 temperature sensors measured the indoor air temperature in the vestibule and the lobby at multiple locations as shown in Figure 1.

\section{Procedure}

The HOBO U30 data logger was set to be communicated with the HOBO link web-based software platform that stored all the data remotely. The other sensors such as HOBO U10, UX90, and MX2301 were launched to record the data at the desired time intervals. They were then deployed at the designated measuring positions to monitor the indoor and outdoor environments, as well as entrance door usage. The measurement of the velocity of the airflow and differential pressure across the entrance doors followed when the door usage was low.

The door area was divided into six sections and both air velocity and differential pressure were simultaneously measured at the center point of each section from the top left point to the bottom right point in order as shown in Figure 2. Two outer doors (door 1 and 2) and one inner door (door 3) were selected. The dimensions of the inner and outer doors are identical. The outer two doors open to the opposite direction outward and inward as shown in Figure 1. The measurement began by opening a measuring door 90 degrees outward when the indoor pressure is stabilized. The door was opened during the course of the measurement. The simultaneous measurement of the two parameters across the entrance doors took approximately 1 minute. All the other doors were closed when the parameters were being measured.

The direction of the airflow was determined by the differential pressure between the outdoor and the vestibule across the outer entrance doors (door 1 and 2) and between the vestibule and the lobby for the inner door (door 3). It was assumed that the pressure inside of the building is greater than the outside and the high side end in the differential pressure transducer was set to be indoor. That is, the high-side end was set to be the vestibule for the door 1 and 2 and the lobby for the door 3 . 


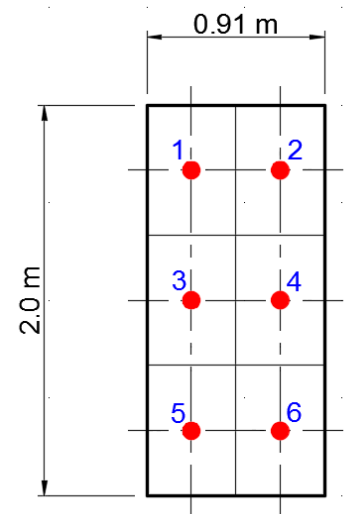

Figure 2: Measuring points for velocity and differential pressure over the entrance door area.

The differential pressure across the entrance doors $P_{\text {diff }}$ in $P a$ was determined as follows:

$$
P_{\text {diff }}=P_{h}-P_{l}
$$

where $P_{h}$ is the high-pressure side and $P_{l}$ is the lowpressure side.

During the measurement of these two parameters, the readings from the instruments were made when the displayed values on the instruments became stable in order to avoid the impact of the highly inconsistent wind gusts. The measurement was restarted if any of the other doors than the measuring one was opened since the use of other doors causes a significant change in the pressure profile in the vestibule. The volumetric flow rate of the airflow $Q$ in $\mathrm{m}^{3} / \mathrm{h}$ through the entrance doors can be defined as follows:

$$
Q=3600 A V
$$

where $A$ is the area of the entrance doors in $\mathrm{m}^{2}$ and $V$ is the velocity of the airflow in $\mathrm{m} / \mathrm{s}$. As from the energy equation, the rate of heat transfer of the airflow $\dot{q}$ in $\mathrm{Kcal} / \mathrm{h}$ is expressed as:

$$
\dot{q}=0.29 Q \Delta t
$$

where $\Delta t$ is a temperature difference in ${ }^{\circ} \mathrm{C}$. A conversion factor of 1.163 was used to convert the heat transfer rate in $\mathrm{Kcal} / \mathrm{h}$ to Watts.

\section{Result}

Figure 3 illustrates one set of measurements for the velocity of the airflow across the entrance doors and the differential pressure. It displays one data set for each door that has the same or similar outdoor wind speeds. All the measured differential pressures were a negative value. As form equation (1), the negative differential pressures showed that the outdoor pressure driven by the wind is greater than the indoor and it determines the direction of the airflow through the entrance doors. To that end, the measured differential pressures indicated that the cold outdoor air flowed from the outdoor to the indoor throughout the entire area of the entrance doors during the course of the measurements when they were opened.

The differential pressure profile across the outer entrance doors (door 1 and 2) showed a similar trend while the outdoor wind speed and direction varied. In general, the average differential pressures at the top were the greatest across the outer doors while the middle was the lowest. This profile in the differential pressure is a notable trend in the results of the measurements for the outer doors. When the outer doors were opened, the wind-driven airflow pressurized the vestibule space and caused air motions from the upper portion to the middle due to a vertical temperature gradient. This characteristic of the air diffusion in the vestibule led such pressure distribution across the outer doors.

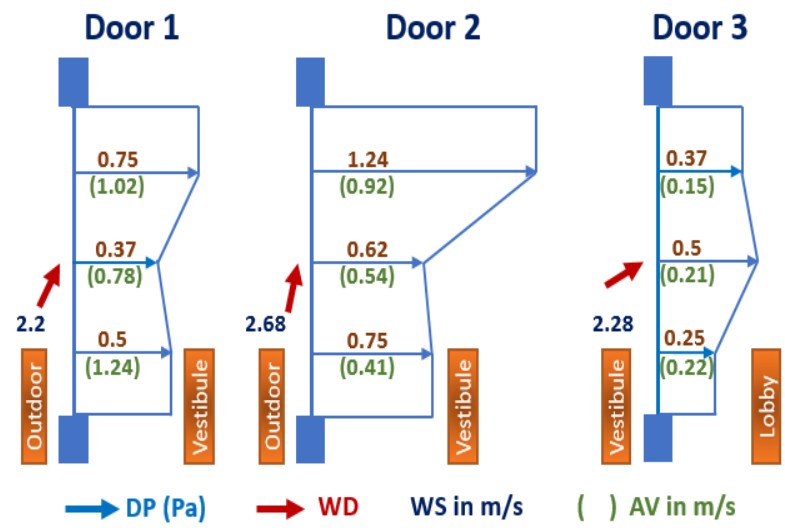

Figure 3: Differential pressure and air velocity profile across the selected doors.

The differential pressure profile for the inner door (door 3) was fairly constant across the door as shown in Figure 3. The differential pressure was lower than that of the outer doors as the wind-driven pressure was lessened when the cold outdoor air mixed with the warmer air in the vestibule. The differential pressure in the middle was greater than the top and bottom, which differs from the pressure profile in the outdoor doors. The pressure profile across the inner door varied with each measurement and no considerable trend was found. Unlike the vestibule, the pressure profile in the inside building, i.e., the lobby area, seems stable as the volume of the space is much larger than the vestibule and the central air-conditioning system consistently supplied the required heats through the ceiling diffusers.

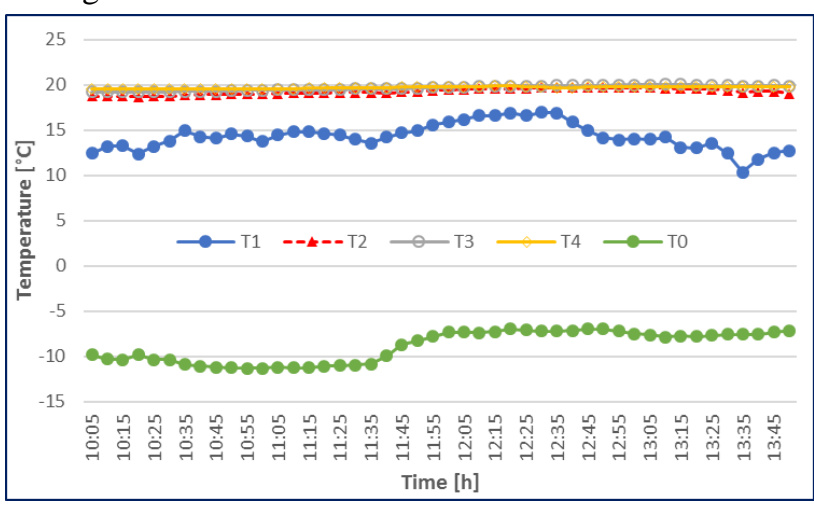

Figure 4: Outdoor and indoor air temperature variations at the measuring points.

Figure 4 shows variations in the temperature of the outdoor air measured by the weather station and the indoor air at the four measuring points at approximately $1.1 \mathrm{~m}$ height. as shown in Figure 1. The outdoor weather 
was very cold and the air temperature (To) ranged from $11.3^{\circ} \mathrm{C}$ to $-7.0^{\circ} \mathrm{C}$. The air temperature in the vestibule (T1) varied significantly within $6.6^{\circ} \mathrm{C}$ band as the cold outdoor air directly affected when the doors were opened. The indoor temperature variations (T2, T3, and T4) were very constant. The average temperature difference between the inner lobby area (T4) and the outer (T2) was only $0.6^{\circ} \mathrm{C}$. The air temperature in the vestibule decreased by the infiltration though a small-sized fan coil unit heated the vestibule. These temperature variations indicated that the impact of the cold outdoor air was fairly limited to the vestibule.

The air velocity of the airflow across the entrance doors varied significantly as shown in Table 2 . The average air velocity (AV) across the door 3 was $0.19 \mathrm{~m} / \mathrm{s}$ while those for the door 1 and 2 were $1.01 \mathrm{~m} / \mathrm{s}$ and $0.62 \mathrm{~m} / \mathrm{s}$, respectively. The air flow rate across the inner door (door 3 ) is thus much lower than the outer doors (door 1 and 2) as the areas of the doors were identical. A larger volume of the cold air flowed through the outer doors in the vestibule due to a great pressure difference between the outdoor and the vestibule, as well as the greater temperature difference. The velocities of the airflow through the entrance doors showed no direct relationship with the outdoor wind speeds. It is noted that the current analytical models and building performance simulations determine the natural airflow rates based on the magnitude of the wind speed as described in the Introduction section.

Table 2 demonstrates how much heat flowed through the selected entrance doors. The heat flows are the function of the air flow rate and the temperature difference as expressed in the energy equation (3). The temperature differences across the outer doors and the inner doors showed a significant difference. The temperature difference across the door 3 (T2-T1) was nearly 3 times lower than that across the outer doors (T1-To). Two main variables such as the air flow rate and the temperature difference across the door 1 and 2 were much higher and the heat transfer rates across the outer entrance doors were much greater than the indoor. As the air velocity of the inflows determined the air flow rate across the entrance doors, it is a dominating parameter for the calculation of the heat transfer rate of the cold airflow.

The greatest differential pressure was found in the outer doors and the heat transfer rate of the data set was the lowest. The differential pressure across the door 3 was relatively lower and constant. The highest one appeared to be $-0.62 \mathrm{~Pa}$. The heat transfer rate of the case where the differential pressure was the lowest was the greatest. The data set in Table 2 showed no direct relationship between the air velocity of the inflows and the heat transfer rate of the airflow in both the outer and inner doors.

\section{Conclusion}

This study developed an experimental method to accurately estimate heat flows through main entrance doors in a college building on a cold winter day. The measurement of the local environmental parameters and differential pressures as well as the air velocity across the entrance doors enabled the accurate quantification of the heat flows by the wind-driven airflow when the doors were opened. The results of the pressure distribution across the entrance doors demonstrated that the air flows toward the inside of the building throughout the opening areas of the outer and inner doors in the vestibule. The majority of the heat flow took place through the outer doors in the vestibule and the presence of the vestibule effectively lessen heat losses from the lobby area conditioned by a central air-conditioning system. The results of the measurements showed no direct relationship between the magnitude of the heat flow and the pressure distribution across the entrance doors. The wind speed has also no relationship with the heat flow. As a result, an advanced method is needed to accurately predict the heat flows through the building entrance doors.

In addition, it is needed to collect more data to analyze the characteristics of the heat flow in different buildings, door types, and seasons. The results can be used to validate the existing methods that have been widely used.

Table 2: Heat flows through inner and outer entrance doors in the vestibule space under different weather conditions.

\begin{tabular}{|c|c|c|c|c|c|c|}
\hline Parameters & \multicolumn{3}{|c|}{ Outer Door (Door 1 \& 2) } & \multicolumn{3}{c|}{ Inner Door (Door 3) } \\
\hline $\mathrm{WS}(\mathrm{m} / \mathrm{s})$ & 1.52 & 2.28 & 0.76 & 1.52 & 2.28 & 1.52 \\
\hline $\mathrm{WD}$ & 132 & 41 & 44 & 27 & 67 & 41 \\
\hline Velocity $(\mathrm{m} / \mathrm{s})$ & 0.83 & 1.01 & 1.19 & 0.25 & 0.16 & 0.19 \\
\hline $\mathrm{DP}(\mathrm{Pa})$ & -1.24 & -0.55 & -1.12 & -0.42 & -0.45 & -0.62 \\
\hline $\mathrm{Q}\left(\mathrm{m}^{3} / \mathrm{h}\right)$ & 5,438 & 6,618 & 7,797 & 1,638 & 1,048 & 1,245 \\
\hline$\Delta \mathrm{T}\left({ }^{\circ} \mathrm{C}\right)$ & 21.7 & 21.8 & 21.8 & 7.7 & 7.9 & 7.6 \\
\hline$\dot{q}$ (Watts) & 39,660 & 48,686 & 57,428 & 4,254 & 2,793 & 3,191 \\
\hline
\end{tabular}

\section{References}

Chen, Q. (2009) Ventilation performnce prediction for buildings: A method overview and recent applications. Building and Environment, 44, 848-858.
Chiu, YH and Etheridge, DW. (2004) Experimental technique to determine unsteady flow in natural ventilation stacks at model scale. Journal of Wind Engineering and Industrial Aerodynamics, 92, 291313. 
Cho, H, Gowri, K, and Liu., B. (2010). Energy saving impact of ASHRAE 90.1 vestibule requirements: modeling of air infiltration through door openings. Richland, WA, USA: PNNL-20026.

Dols, WS and Polidoro, BJ. (2015) CONTAM User Guide and Program Documentation Version 3.2.

Ernest, DR, Bauman, FS, and Arens, EA. (1992) The effects of external wind pressure distributions on wind-induced air motion inside buildings. Journal of Wind Engineering and Industrial Aerodynamics, 4144, 2539-2550.

Feustel, HE. (1998) COMIS - An International Multizone Air-Flow and Contaminant. LBNL.

Goubran, S, Qi, D, Saleh, WF, and Wang, L. (2017) Comparing methods of modeling air infiltration through building entrances and their impact on building energy simulations, Energy and Buildings 138, 579-590.

Gowri, K, Winiarski, D and Jarnagin, R. (2009). Infiltration modeling guidelines for commercial building energy analysis. Richland, WA, USA: PNNL-18898.

Han, G, Srebric, J, and Enache-Pommer, E. (2015) Different modeling strategies of infiltration rates for an office building to improve accuracy of building energy simulation. Energy and Buildings 86, 288-295.

Lin Du. (2009). Air Infiltration through Revolving Doors. Master's Thesis.
Mahajan, G, Cho, H, Shanley, K and Kang, D. (2015). Comprehensive modeling of airflow rate through automatic doors for low-rise buildings. Building and Environment 87:72-81.

Muehleisen, RT and Patrizi, S. (2013) A new parametric equation for the wind pressure coefficient for low-rise buildings. Energy and Buildings 57, 245-249.

Shaw, CY and Tamura, GT. (1977). The calculation of air infiltration rates caused by wind and stack action for tall buildings. ASHRAE Trans. 2(83):145-58.

Swami, MV and Chandra S. (1987) Procedures for calculating natural ventilation airflow rates in buildings. ASHRAE Research Project 448-RP.

University of Strathclyde. (2002) The ESP-r System for Building Energy Simulation User Guide Version 10 Series.

US Department of Energy. (2018) EnergyPlus Engineering Reference.

Walker, IS and Wilson, D. (1990). The alberta infiltration model: AIM-2. Technical Report No. 71, Edmonton, Alberta, Canada.

Younes C, Shdid C, and Bitsuamlak, G. (2011). Air infiltration through building envelopes: a review. Build Phys 35, 3:267-302.

Yuill, GK, Upham, R, and Hul, Chen. (2000). Air leakage through automatic doors. ASHARE transactions V 106. 